\title{
Kompetensi Pedagogik Mahasiswa Program Studi Pendidikan Matematika dalam Menyusun Tes Matematika HOTS
}

\author{
Welas Listiani $^{1)}$, Yunis Sulistyorini ${ }^{2)}$ \\ ${ }^{1,2)}$ IKIP Budi Utomo Malang, Indonesia \\ Email: welas.listiani1981@gmail.com, yunis.sulistyorini@gmail.com
}

\begin{abstract}
This study to describe the pedagogic competence of students of Mathematics Education Study Program at IKIP Budi Utomo in compiling Mathematics tests based on HOTS. It is qualitative research with Focus Group Discussion (FGD) technique. The results showed that pedagogic competence to develop assessment and evaluation instruments in Mathematics learning requires other pedagogical skills, namely: the ability to understand the characteristics of learners, the theory of learning, utilizing information and communication technology, and the ability to communicate. Students can only arrange HOTS questions at C4 level or analyze and still need help from lecturers or facilitators to be able to prepare HOTS questions properly.
\end{abstract}

Keywords : Pedagogic Competence, Math Test, HOTS

\begin{abstract}
ABSTRAK
Penelitian ini untuk mendeskripsikan kompetensi pedagogik mahasiswa Program Studi Pendidikan Matematika di IKIP Budi Utomo dalam menyusun tes Matematika berbasis HOTS. Ini ini adalah penelitian kualitatif dengan teknik Focus Group Discussion (FGD). Hasil penelitian menunjukkan bahwa kompetensi pedagogik mengembangkan instrument penilaian dan evaluasi dalam pembelajaran Matematika memerlukan kemampuan pedagogik yang lain yaitu: kemampuan memahami karakteristik peserta didik, teori belajar, memanfaatkan teknologi informasi dan komunikasi, dan kemampuan berkomunikasi. Mahasiswa hanya dapat menyusun soal HOTS pada level $\mathrm{C} 4$ atau menganalisis dan masih memerlukan bantuan dari dosen atau fasilitator untuk dapat menyusun soal HOTS dengan baik.
\end{abstract}

Kata Kunci : Kompetensi Pedagogik, Tes Matematika, HOTS 


\section{PENDAHULUAN}

Guru yang kompeten diperlukan dalam pendidikan untuk dapat mewujudkan tujuan pendidikan nasional. Untuk itu, seorang guru perlu mempunyai kompetensi pedagogik, kepribadian, sosial, dan profesional. Kompetensi pedagogik adalah kompetensi pembeda profesi guru dengan profesi lainnya (Shulman dalam Evens, M. dkk : 2015). Kompetensi pedagogik bersifat komprehensif meliputi kemampuan guru dalam berbagai aspek belajar dan mengajar yang harus dikembangkan sejalan dengan perkembangan zaman seperti teknologi canggih dan revolusi ilmu pengetahuan (Novianti \& Nurlaelawati, 2019). Kompetensi ini digunakan guru untuk mengelola pembelajaran dengan efektif yang meliputi : kemampuan mengenali setiap peserta didik, membuat dan melaksanakan rencana pelakanaan pembelajaran (RPP), evaluasi, dan mengaktualissikan potensi peserta didik (Anwar, 2019).

Paparan tersebut menunjukkan bahwa kompetensi pedagogik adalah kompetensi unik guru yang dipakai dalam pembelajaran untuk mencapai tujuan pendidikan nasional. Oleh karena itu, mahasiswa khususnya Mahasiswa Program Studi Pendidikan Matematika di IKIP Budi Utomo harus mengetahui atau menguasai kompetensi pedagogik seorang guru agar mereka dapat menjadi guru yang kompeten. Kompetensi yang dapat digunakan untuk mengetahui berhasil atau tidaknya suatu tujuan pendidikan yaitu melakukan penilaian dan evaluasi pembelajaran (Permendiknas No: 16/2007, 2007). Kompetensi tersebut mengharapakan mahasiswa dapat membuat soal Matematika secara mandiri tanpa harus mengutip dari buku atau sumber belajar lainnya karena pemerintah Indonesia sudah menganjurkan satuansatuan pendidikan untuk menerapkan konsep belajar Higher Order Thinking Skills (HOTS).

HOTS adalah kemampuan untuk mencari hubungan, membuat manipulasi, dan mengubah pengetahuan dan pengalaman dengan kritis kreatif untuk memecahkan masalah (Dinni, 2018). Soal HOTS adalah soal yang digunakan untuk mengetahui keterampilan berfikir tingkat tinggi, kontekstual, soal non rutin serta bentuk soal yang beragam (Sa'idah et al., 2018).

Keterampilan itu adalah keterampilan berfikir dengan logis, kritis, kreatif, dan pemecahan masalah secara mandiri (Setiawati et al., n.d.). Berfikir secara kritis 
dan kreatif adalah dua kemampuan dasar yang dapat mendingkatkan kemampuan peserta didik untuk menyikapi permasalahan dengan kritis serta memecahkan masalah dengan kreatif untuk memperoleh suatu kebaharuan dan bermanfaat dalam kehidupan (Budiman \& Jailani, 2014). Dapat disimpulkan bahwa HOTS merupakan suatu keterampilan yang memerlukan penalaran atau logika secara kritis dan kreatif dalam memecahkan masalah.

HOTS memiliki manfaat dalam pembelajran yaitu : belajar akan lebih efektif, kemampuan intelektual guru akan meningkat dalam mengembangkan HOTS, guru harus selalu menyiapkan soal pertanyaan non rutin untuk peserta didik (Ariandari, 2015). Dapat dikatakan bahwa HOTS akan selalu mengembangkan kemampuan evaluasi guru sehingga pembelajaran lebih efektif dan setiap peserta didik akan dapat memiliki pemecahan masalah yang berbeda meskipun menghadapi masalah yang sama.

Taksonomi Bloom revisi memiliki enam level kognitif yaitu C1 (mengingat), C2 (memahami), C3 (menerapkan), C4 (menganalisis), C5 (mengevaluasi), dan C6 (mencipta). Kriteria soal HOTS berada pada level penalaran atau level 3 meliputi menganalisis, mengevaluasi, dan mencipta. Ini sesuai dengan pernyataan "level penalaran meliputi menganalisis (C4), mengevaluasi (C5), dan mencipta (C6) (Setiawati et al., n.d.).

Berdasarkan uraian tersebut, penelitian ini bertujuan mendeskripsikan kemampuan pedagogik mahasiswa Program Studi Pendidikan Matematika di IKIP Budi Utomo dalam menyusun tes Matematika HOTS.

\section{METODE PENELITIAN}

Penelitian ini merupakan penelitian deskriptif kualitatif menggunakan teknik Focus Group Discussion (FGD). Instrumen yang digunakan adalh observasi dan proyek kerja mahasiswa. Subyek penelitian adalah mahasiswa calon guru Matematika di IKIP Budi Utomo yang sudah menempuh kuliah Evaluasi Pendidikan pada tahun akademik 2019/2020. Data dianalisis dengan cara reduksi, kategorisasi, sintesisasi, serta menyusun "hipotesis kerja". 


\section{HASIL DAN PEMBAHASAN}

Proyek kerja mahasiswa calon guru Matematika dalam menyusun tes Matematika HOTS terdiri dari tiga kegiatan yaitu: persiapan, pelaksanaan, dan laporan. Persiapan dilakukan untuk mengidentifikasi kemampuan mahasiswa dalam mengenali karakteristik siswa. Selain itu, juga digunakan untuk mengidentifikasi pemahaman mahasiswa terhadap teori belajar (Permendiknas No: 16/2007, 2007). Dapat disimpulkan bahwa tahap persiapan merupakan tahap analisis kemampuan mahasiswa untuk memahami kesiapan peserta didik dalam belajar.

Selanjutnya, tahap pelaksanaan digunakan untuk mengetahui kreatiftas mahasiswa calon guru Matematika dalam menggunakan Teknologi Informasi dan Komunikasi (TIK) dalam pembelajaran Matematika serta kemampuan mereka dalam membuat instrumen penilaian dan evaluasi (Permendiknas No: 16/2007, 2007). Dengan kata lain, tahap ini merupakan tahap untuk mengetahui keahlian mahasiswa dalam menyusun tes Matematika HOTS.

Tahap terakhir yaitu laporan digunakan untuk mengetahui kemampuan berkomunikasi mahasiswa (Permendiknas No: 16/2007, 2007). Hal ini menyebabkan calon guru Matematika harus memiliki kemampuan komunikasi yang baik dalam pembelajaran Matematika.

Penyusunan tes Matematika HOTS dilakukan oleh 3 kelompok mahasiswa dengan kriteria kelompok I merupakan mahasiwa yang sudah memiliki pengalaman kerja dalam mengajar di sekolah atau bimbingan belajar, kelompok II adalah mahasiswa yang memiliki pekerjaan sebagai staf sekolah, dan kelompok III yaitu mahasiswa yang belum bekerja di sekolah.

\section{Persiapan}

Hasil observasi pada tahap persiapan menunjukkan bahwa kelompok I sudah memahami karakteristik siswa. Mereka menunjukkan adanya peserta didik yang mampu mengerjakan soal HOTS dengan mudah. Kelompok II dan III memiliki pemikiran bahwa soal HOTS adalah soal yang tidak mudah diselesaikan oleh peserta didik.

Sebenarnya soal HOTS adalah soal yang memerlukan proses berfikir kritis dan kreatif yang memerlukan keterampilan berfikir tingkat tinggi. Keterampilan HOTS bukan sekedar keterampilan mengingat namun memerlukan pemikiran yang 
lebih tinggi (Sa'idah et al., 2018). Sehingga jika ada peserta didik yang dengan mudah mengerjakan soal HOTS maka ada kemungkinan mereka sudah pernah menjumpai soal serupa sehingga menjadi ingatan bagi mereka.

Mahasiwa menganggap bahwa soal HOTS adalah soal yang sukar untuk dipecahkan. Jika demikian maka Matematika akan menjadi ilmu yang menakutkan bagi peserta didik. Padahal Soal HOTS tidak selalu soal yang sulit untuk diselesaikan. Hal ini ditegaskan oleh pernyataan "the implementation of HOTS in the teaching and learning of mathematics is essential to change the stigma of the society on the difficulty of mathematics. HOTS can also attract students to foster their interest in mathematics"(Abdullah et al., 2017). Artinya, HOTS akan mengubah stigma masyarakat tentang matematika yang sulit menjadi matematika yang memiliki daya tarik. Hal itu menunjukkan bahwa peserta didik atau siswa akan lebih tertarik pada Matematika karena adanya HOTS.

Ada kriteria soal HOTS yang harus diperhatikan oleh mahasiwa calon guru Matematika. Kriteria tersebut yaitu: mengukur kemampuan berpikir yang lebih tinggi tinggi, divergen, multirepresentasi, kontekstual, dan bentuk soal beragam (Setiawati et al., n.d.). Kemampuan berfikir tingkat tinggi ditunjukkan oleh level soal HOTS yaitu C4, C5, atau C6. HOTS bersifat divergen artinya soal HOTS bersifat open ended atau memiliki lebih dari satu selesaian atau cara penyelesaian. HOTS juga bersifat multirepresentatif, maksudnya soal HOTS dapat disajikan dalam berbagai macam kondisi seperti verbal, simbol, atau gambar. Soal HOTS juga merupakan soal-soal yang kontekstual disesuaikan dengan lingkungan hidup sehari-hari peserta didik dan dapat disajikan dalam bentuk soal subjektif atau objektif.

Dalam hal penguasaan teori belajar diperoleh data bahwa semua kelompok sudah dapat memahami taksonomi Bloom. Namun mahasiswa mengalami kesulitan memberikan contoh soal HOTS. Namun, ketika mereka diminta untuk menganalisis suatu soal termasuk HOTS atau bukan HOTS, mereka dapat menentukan level HOTS dari soal tersebut.

Dengan kata lain mahasiswa calon guru Matematika masih memerlukan pendampingan dalam menyusun soal Matematika HOTS. Mereka memerlukan penguatan dari dosen atau fasilitator untuk memantabkan ide atau gagasannya. 


\section{Pelaksanaan}

Dalam tahap pelaksanaan, mahasiswa sudah menggunakan atau memanfaatkan teknologi informasi dan komunikasi dalam menyusun tes Matematika HOTS. Ini merupakan kompetensi guru yang ada dalam Permendiknas No: 16/2007. Mahasiswa memanfaatkan whatsapp, zoom meeting, atau browsing materi HOTS di internet serta memanfaatkan buku-buku yang berhbungan dengan HOTS.

Selanjutnya, untuk mengembangkan instrumen penilaian dan evaluasi diperoleh data bahwa setiap kelompok sudah menggunakan kompetensi dasar yang sesuai dengan kriteria soal HOTS. Namun, soal yang dibuat hanya berada pada level $\mathrm{C} 4$ atau menganalisis.

Hal tersebut menunjukkan bahwa mereka belum menguasai konsep HOTS dengan baik. Untuk dapat menyusun soal HOTS level C5 dan C6 memerlukan bantuan dosen atau fasilitator. Ini terjadi karena belum ada instrumen peniliaan yang dirancang khusus untuk melatih HOTS atau keterampilan berfikir tingkat tinggi (Budiman \& Jailani, 2014).

Kunci jawaban soal HOTS yang terdapat dalam pedoman penskoran menunjukkan bahwa soal HOTS yang dibuat dapat diselesaikan dengan cara yang lain. Salah satu ciri HOTS yaitu bersifat divergen, artinya soal tersebut memberi kesempatan kepada peserta didik untuk dapat memberikan jawaban yang beragam sesuai dengan pemikiran dan sudut pandang masing-masing peserta didik (Setiawati et al., n.d.).

\section{Laporan}

Tahap laporan merupakan tahap presentasi dari setiap kelompok untuk menyampaikan hasil proyeknya secara lisan dan tulisan. Ini merupakan kompetensi pedagogik mahasiwa calon guru untuk berkomunikasi dengan baik (Permendiknas No: 16/2007, 2007). Dalam tahap ini, mahasiswa sudah mampu berkomunikasi dengan baik dengan lisan dan tulisan. Mereka mampu menerima saran atau kritik dari orang lain. Mereka menyadari bahwa mereka harus lebih banyak belajar tentang soal HOTS karena dalam menyusun soal HOTS tidak boleh asal-asalan. Tidak semua soal HOTS merupakan soal yang sukar untuk diselesaikan karena soal HOTS adalah kontekstual. 


\section{SIMPULAN}

Menyusun tes merupakan suatu kompetensi pedagogik yang harus dimiliki atau dikuasai oleh mahasiswa Program Studi Pendidikan Matematika sebagai calon guru Matematika. Mereka harus mampu mengembangkan instrument penilaian dan evaluasi. Kemampuan ini didukung oleh kemampuan pedagogik lainnya yaitu : pemahaman terhadap karakteristik peserta didik, teori belajar, pemanfaatan teknologi informasi dan komunikasi, dan kemampuan berkomunikasi secara lisan dan tulisan.

Mahasiswa calon guru Matematika masih memerlukan pendampingan dalam menyusun tes Matematika HOTS karena hanya dapat membuat soal HOTS level C4 atau menganalisis. Oleh karena itu perlu ada penelitan lebih lanjut atau pelatihan tentang penyusunan tes Matematika HOTS agar mereka memiliki kemampuan yang bagus dalam menyusun tes Matematika HOTS.

\section{REFERENSI}

Abdullah, A. H., Mokhtar, M., Halim, N. D. A., Ali, D. F., Tahir, L. M., \& Kohar, U. H. A. 2017. Mathematics teachers' level of knowledge and practice on the implementation of higher-order thinking skills (HOTS). Eurasia Journal of Mathematics, Science and Technology Education. https://doi.org/10.12973/eurasia.2017.00601a

Anwar, B. 2019. Kompetensi Pedagogik sebagai Agen Pembelajaran. Shaut Al Arabiyyah. https://doi.org/10.24252/saa.v6i2.7129

Ariandari, W. P. 2015. Mengintegrasikan Higher Order Thinking dalam Pembelajaran Creative Problem Solving. Seminar Nasional Matematika Dan Pendidikan Matematika Uny 2015.

Budiman, A., \& Jailani. 2014. Pengembangan Instrumen Asesmen Higher Order Thinking Skill (HOTS) ... ( Agus Budiman, Jailani ) - 139. Jurnal Riset Pendidikan Matematika.

Dinni, H. N. 2018. HOTS ( High Order Thinking Skills ) dan Kaitannya dengan Kemampuan Literasi Matematika. Prisma.

Novianti, N., \& Nurlaelawati, I. 2019. Pedagogical Competence Development Of University Teachers With Non-Education Background: The Case Of A Large University Of Education In Indonesia. International Journal of Education. https://doi.org/10.17509/ije.v11i2.15711

Permendiknas No: 16/2007, L. 2007. Peraturan Menteri Pendidikan Nasional Nomor 
16 Tahun 2007. In vervalsp.data.kemdikbud.go.id.

Sa'idah, N., Yulistianti, H. D., \& Megawati, E. 2018. Analisis Instrumen Tes Higher Order Thinking Matematika SMP. Jurnal Pendidikan Matematika. https://doi.org/10.22342/jpm.13.1.6619.41-54

Setiawati, W., LPMP Kalimantan Timur Oktavia Asmira, Mp., LPMP Kepulauan Bangka Belitung Yoki Ariyana, M., Widyaiswara PPPPTK IPA Bandung Reisky Bestary, M., Widyaiswara LPMP Provinsi Riau Ari Pudjiastuti Widyaiswara PPPPTK PKn dan IPS Batu, Mp., \& Jenderal Guru dan Tenaga Kependidikan Kementerian Pendidikan dan Kebudayaan, D. (n.d.). Buku Penilaian Berorientasi Higher Order Thinking Skills. 